\title{
Analysis of tunnel considering Modified Mohr-Coulomb criterions
}

\author{
S Rukhaiyar and NK Samadhiya \\ Department of Civil Engineering \\ Indian Institute of Technology Roorkee \\ Roorkee, India \\ saurav.rukhaiyar@gmail.com
}

\begin{abstract}
Analysis of tunnels and underground excavations requires a realistic prediction of strength and deformation characteristics of rockmass. The strength characteristics of rockmass must be determined by laboratory testing such as triaxial test but generally, classification approach is used to predict the triaxial strength of rockmass. A number of empirical criterion had been developed in past to simulate the triaxial behavior of rockmass. The Generalized Hoek-Brown (GHB) criterion (2002) is most widely and generally used. A new triaxial strength criterion was presented recently known as Modified Mohr-Coulomb (MMC) criterion. Probabilistic approach combined with various classification approaches is used to predict the triaxial strength of rockmass giving much higher sense of confidence.
\end{abstract}

The GHB and MMC criterion are nonlinear in nature. However, the continuum numerical codes and analysis methods generally do not accept such nonlinear criterion and may allow only Mohr-Coulomb linear criteria. The researcher generally fit a linear equation on nonlinear data point with in certain range of minor principal stress to calculate the equivalent MohrCoulomb criterion parameter i.e. cohesion and angle of internal friction. This approach retains the nonlinear behavior of the rockmass.

The present article discusses in detail the calculation of triaxial data point for five different rockmass data from tunnel cases published in literature. The triaxial data points are calculated based on GHB and MMC criterions. Equivalent Mohr-Coulomb parameters are calculated by fitting a linear equation on the non-linear data point. Analysis of unsupported tunnel case is done with the help of convergence confinement method. A quantitative comparison between MMC and GHB criterion is done in light of the analysis results. MMC criterion predicts a lower value of equivalent cohesion while a higher value of angle of internal friction. The response of tunnel predicted by MMC criterion are on lower side but comparable.

Keywords-modified mohr coulomb criterion; generalized hoek brown criterion; triaxial strength; convergence confinement method

\section{INTRODUCTION}

Elasto-plastic continuum analyses are generally carried out to predict the response of underground structures. The analyses require constitutive models for the material nearby. Mohr Coulomb linear model are generally used as contitutive model. The Mohr-Coulomb model parameters i.e. cohesion (c) and angle of internal friction $(\phi)$ are evaluated based on triaxial test conducted on material specimen under various confining pressure. However, the typical triaxial test on rockmass is very cumbersome, time consuming and expensive. Generally field observation in association with classification approach is used to assess the behavior of rockmass.

However, some researchers are of the opinion that the behavior of rock mass is non-linear under triaxial state of stress [1-8]. The non-linearity in strength must be incorporated while analyzing the rock structure. Hoek -Brown criterion [5] is the most commonly used nonlinear triaxial strength criterion presented for rockmass. The strength criterion undergone various modifications and a Generalized Hoek Brown (GHB) criterion was presented by Hoek et al. [6]. The GHB criterion has a history of development which incorporated the experience of various researchers in real field condition. The GHB consider only one classification system which is also based on visual inspection of rockmass.

Recently a new criterion was presented by Singh and Singh [8] as Modified Mohr-Coulomb criterion (MMC) which also considers the nonlinearity in strength of rockmass under triaxial state of stress. The criterion is based on the critical state concept [2]. The criteria can consider any classification system for evaluating the triaxial strength of rockmass.

To incorporate the effect of non-linearity while analyzing any rock structure, Linearization of triaxial datapoint obtained from the strength criterion in a given range of minor principal stress is done. The equivalent Mohr-coulomb (EMC) parameters are obtained from linearized data is used for the analysis. Present papers aims to predict the triaxial strength of the five rockmass data collected from the literature using Modified Mohr-Coulomb (MMC) criterion. Equivalent MohrCoulomb parameters (c and $\varphi$ ) were estimated by linearization of triaxial datapoint for a given range of minor principal stress. An elasto-plastic analysis of a hypothetical case of tunnel was carried out using the analytical solution given by CarranzaTorres [9] known as 
TABLE I. REPRESENTATIVE VALUES OF THE ROCKMASS

\begin{tabular}{|l|l|l|l|l|l|l|l|l|l|l|}
\hline $\begin{array}{l}\text { SI } \\
\text { No. }\end{array}$ & Rock Type & $\begin{array}{l}\text { UCS } \\
\mathbf{M P a})\end{array}$ & $\begin{array}{l}\mathbf{E}_{\mathbf{i}} \\
\mathbf{( G P a )}\end{array}$ & $\begin{array}{l}\text { Unit wt } \\
\mathbf{( g m / c c )}\end{array}$ & $\begin{array}{l}\text { RQD } \\
\mathbf{( \% )}\end{array}$ & $\mathbf{R M R}$ & GSI & $\mathbf{Q}$ & Name of site & Reference \\
\hline 1 & Andesite & 93 & 41.9 & 2.37 & 41 & 40 & 46 & 0.56 & Urus Dam, Turkey & {$[17]$} \\
\hline 2 & Basalt & 142 & 40 & 2.40 & 15 & 44 & 46 & 0.63 & Urus Dam, Turkey & {$[17]$} \\
\hline 3 & Limestone & 62.3 & 31.42 & 2.66 & 69 & 38 & 51 & 1.88 & Guledar Dam, Turkey & {$[18]$} \\
\hline 4 & Sandstone & 64.7 & 27.20 & 2.70 & 34 & 38 & 41 & 0.45 & Guledar Dam, Turkey & {$[18]$} \\
\hline 5 & Limestone & 43.85 & - & 2.30 & 20 & 42 & 43 & 0.88 & Raghadan Tunnel, Jordan & {$[19-20]$} \\
\hline
\end{tabular}

convergence confinement method. A quantitative comparison with GHB criterion was also carried out. The response of tunnel considering Hoek-Brown parameters directly using analytical solution given by [10] and by using equivalent Mohr-Coulomb criterion by linearization of the generalized Hoek-Brown criterion was carried out using the analytical solution given by Carranza-Torres [9].

\section{STRENGTH CRITERIA}

\section{A. Modified Mohr Coulomb (MMC) Criterion}

Singh and Singh [8] proposed a new non-linear criterion for rockmass known as Modified Mohr-Coulomb criterion. The strength criterion incorporates the critical state concept [2]. The criterion for jointed rock mass is presented as:

$$
\begin{gathered}
\sigma_{1}-\sigma_{3}=\sigma_{\text {cmass }}+\frac{2 \sin \phi_{j 0}}{1-\sin \phi_{j 0}} \sigma_{3}-\frac{1}{\sigma_{c i}} \frac{\sin \phi_{j 0}}{1-\sin \phi_{j 0}} \sigma_{3}^{2} \\
\left(\text { for } 0 \leq \sigma_{3} \leq \sigma_{c i}\right)
\end{gathered}
$$

Where $\sigma 1$ and $\sigma 3$ are the major and minor principal stresses. Parameter $\sigma \mathrm{ci}$ and $\sigma \mathrm{cmass}$ are uniaxial compressive strength of intact and jointed rockmass. $\varphi$ jo is angle of internal friction of jointed rockmass corresponding to very small confining pressure $\left(\sigma_{3} \rightarrow 0\right)$ and is estimated from the relationship:

$$
\sin \phi_{j 0}=\frac{(1-S R F)+\frac{\sin \phi_{i 0}}{1-\sin \phi_{i 0}}}{(2-S R F)+\frac{\sin \phi_{i 0}}{1-\sin \phi_{i 0}}}
$$

$\varphi_{\text {io }}$ is angle of internal friction of intact rock corresponding to very small confining pressure i.e. $\sigma_{3} \rightarrow 0$ [11]

$\mathrm{SRF}$ is strength reduction factor and is calculated as:

$$
S R F=\frac{\sigma_{\text {cmass }}}{\sigma_{c i}}
$$

\section{B. Generalised Hoek and Brown (GHB) Criterion}

The generalised Hoek and Brown criterion [6] for the rockmass is presented as:

$$
\begin{aligned}
& \sigma_{1}=\sigma_{3}+\sigma_{c}\left(m_{b} \frac{\sigma_{3}}{\sigma_{c}}+S\right)^{a} \\
& m_{b}=m_{i} \exp \left(\frac{G S I-100}{28-14 D}\right)
\end{aligned}
$$

$$
S=\exp \left(\frac{G S I-100}{9-3 D}\right)
$$

$$
a=\frac{1}{2}+\frac{1}{6}\left(e^{\frac{-G S I}{15}}-e^{\frac{-20}{3}}\right)
$$

Where $\sigma 1$ and $\sigma 3$ are the major and minor principal stresses, $\sigma c$ is the uniaxial compressive strength of the intact rock obtained from statistical analysis of triaxial test data, mi is an intact rock constant and D is a rockmass disturbance factor. GSI is the Geological strength index obtained by the visual inspection of rockmass. Some other methods were also presented by some researchers to calculate the GSI value like rock volume method [12].

For the present analysis it is considered that the blasting is very good with minimal disturbance to the confined rockmass surrounding the rock structure. Hence, D $=0$ has been considered throughout this paper.

\section{ROCKMASS DATA}

For the present study, the database of rockmass had been selected for which the rockmass classification data is available in term of RQD [13], RMR [14], Q system [15] and GSI [16]. Table I show the database of the rockmass used in the present study.

The classification of rockmass was presented based on the RQD, RMR and Q system.

Table II show the classification of the rockmass of the database considered for the present study. An overall classification is also presented based on other classification system provided and judgement. 
TABLE II CLASSIFICATION OF THE ROCKMASS CONSIDERED FOR THE PRESENT STUDY

\begin{tabular}{|l|l|l|l|l|}
\hline $\begin{array}{l}\text { SI } \\
\text { No. }\end{array}$ & $\begin{array}{l}\text { Based on } \\
\text { RQD }\end{array}$ & $\begin{array}{l}\text { Based on } \\
\text { RMR }\end{array}$ & $\begin{array}{l}\text { Based on Q } \\
\text { value }\end{array}$ & Overall \\
\hline 1 & Poor & Poor & Very Poor & Poor \\
\hline 2 & Very Poor & Fair & Very Poor & Poor \\
\hline 3 & Fair & Poor & Poor & Poor \\
\hline 4 & Poor & Poor & Very Poor & Poor \\
\hline 5 & Very Poor & Fair & Very poor & Poor \\
\hline
\end{tabular}

\section{A. Triaxial Simulation of intact rock}

Both the rockmass strength criteria under consideration need parameters which require triaxial testing of the intact rock specimen. The parameters are $\varphi$ io in the Modified Mohr Coulomb criterion while parameters $\sigma \mathrm{c}$ and $\mathrm{mi}$ in the generalized Hoek-Brown criterion are calculated based on triaxial test results of intact rock.

The $\sigma \mathrm{c}$ and mi value can be calculated using the roclab software. Singh et al. [11] reported that pio may be obtained from triaxial test data as:

$$
\operatorname{Sin} \phi_{i 0}=\frac{B_{i}}{2+B_{i}}
$$

where,

$$
B_{i}=-2 A_{i} \sigma_{c i}
$$

and

$$
A_{i}=\frac{\sum\left(\sigma_{1}-\sigma_{3}-\sigma_{c i}\right)}{\sum\left(\sigma_{3}^{2}-2 \sigma_{c i} \sigma_{3}\right)} \quad \text { for } 0<\sigma_{3} \leq \sigma_{c i}
$$

A number of triaxial strength criteria have been presented by various researchers to predict the value of major principal stress at failure for intact rock corresponding to a minor principal stress. Most recently Shen et al. [21] presented a simplified strength criterion for intact rock based on rock type and uniaxial compressive strength. The Shen strength criterion is presented as:

$$
\sigma_{1}=\sigma_{3}+\sigma_{c i}+B \sigma_{c i}+\left(\frac{\sigma_{3}}{\sigma_{c i}}\right)^{0.5}
$$

where, $B=a \sigma_{c i}^{b+1}$

$\sigma_{\mathrm{ci}}$ is the uniaxial compressive strength of intact rock in MPa. $\mathrm{a}$ and $\mathrm{b}$ are constants which depend upon rock type. Shen et al. [21] presented a table for $\mathrm{a}$ and $\mathrm{b}$ for eight specific rock type. However, the value of a and $b$ may be taken as 2.0 and 0.97 respectively in general, if no data regarding rock type is available or for rock type other than the eight specific ones.

A parabolic strength criterion for intact rock was also presented by Singh and Singh [22] as:

$$
\sigma_{1}=A \sigma_{3}^{2}-2 A \sigma_{3} \sigma_{c i}+\sigma_{c i}+\sigma_{3} \text { for } 0<\sigma_{3} \leq \sigma_{c i}
$$

$$
\sigma_{1}=-A \sigma_{c i}^{2}+\sigma_{c i}+\sigma_{3} \text { for } \sigma_{3}>\sigma_{c i}
$$

A is the criterion parameter, which can be estimated from $\sigma c i$ as:

$$
A=-3.97 \sigma_{c i}^{-1.10}
$$

where $\sigma \mathrm{ci}$ is uniaxial compressive strength of intact rock in $\mathrm{MPa}$ within a range of $7-500 \mathrm{MPa}$.

The above mentioned two strength criteria for intact rock have been used to simulate five triaxial data point for intact rock. The major principal stress at failure have been estimated corresponding to minor principal stress of $0,2,4,6$ and 10 MPa for each rock. The average value of major principal stress from the two strength criterion is used to calculate the value of mi, oc and Sinpio. The value of Sinpio, mi and $\sigma c$ is presented in Table V. This approach is used so as to have uniformity between GHB and MMC criterion in terms of intact rock strength parameters.

\section{CALCULATION OF ELASTIC AND PLASTIC PARAMETERS OF THE ROCKMASS}

\section{A. Calculation of uniaxial strength of rockmass ( $\left.\sigma_{\text {cmass }}\right)$ and} Elastic Modulus of rockmass ( $\left.E_{\text {mass }}\right)$

The modified Mohr Coulomb (MMC) criterion requires SRF value as explained in previous section (Equation 3). The $\mathrm{SRF}$ calculation requires an estimate of $\sigma \mathrm{cmass}$ i.e. uniaxial compressive strength of rockmass. A number of criteria were presented by previous researchers for the calculation of uniaxial strength of jointed rockmass, which are based on various classification systems. Table III present twelve such strength criteria considered in present study. The strength of rockmass is calculated from all the twelve criteria which consider different classification system. The value of rockmass strength obtained from the twelve equations is not a unique value and found to be very scatter. Probabilistic analysis is in vogue to have a better representation of variability [23-24]. To get a unique representative value of rockmass strength, Weibull's probability distribution was fitted into the all these twelve value. This approach of using probability distribution gives a confidence level in the representative value of parameter.

The Weibull's probability distribution function is defined as:

$$
P=1-e^{-\left(\frac{\sigma-\sigma_{u}}{\sigma_{a}}\right)^{m}}
$$

Where, $\mathrm{P}=$ Probability of occurrence, $\sigma=$ variable parameter (stress), $\sigma u=$ minimum value of the variable below which the probability of occurrence is zero. $\sigma \mathrm{a}$ is the scale parameter and $\mathrm{m}$ is the shape parameter representing the steepness of the plot.

The Weibull's probability distribution is converted into linear function form as: 


$$
\ln \ln \left[\frac{1}{1-p}\right]=m \ln \left(\sigma-\sigma_{u}\right)-m \ln \left(\sigma_{a}\right)
$$

The value of $\sigma_{\mathrm{u}}$ was assumed from dataset and parameter $\mathrm{m}$ and $\sigma \mathrm{a}$ were obtained by fitting a straight line to Equation 17. Several trials were made to fix the value of ou such that best coefficient of correlation is achieved. The value of variable parameter corresponding to $50 \%$ of occurrence is considered as representative value of parameter. The rockmass strength corresponding to $50 \%$ or 0.5 probability of occurrence is designated as representative value rockmass strength ( $\sigma \mathrm{cmass})$. Fig.1 shows the typical Weibull's distribution fitted for the calculation of uniaxial strength of rockmass. Table $\mathrm{V}$ present the representative value of $\sigma \mathrm{cmass}$ for all the rockmass.

TABLE III VARIOUS UNIAXIAL ROCKMASS STRENGTH CRITERION CONSIDERED FOR PRESENT STUDY

\begin{tabular}{|c|c|c|}
\hline Sl. No. & $\begin{array}{l}\text { Referenc } \\
\text { e }\end{array}$ & Criteria \\
\hline \multicolumn{3}{|c|}{ Based on RMR classification } \\
\hline 1 & [25] & $\frac{\sigma_{\mathrm{cm}}}{\sigma_{\mathrm{ci}}}=\mathrm{e}^{\frac{7.65(\mathrm{RMR}-100)}{100}}$ \\
\hline 2 & [26] & $\frac{\sigma_{\mathrm{cm}}}{\sigma_{\mathrm{ci}}}=\mathrm{e}^{\frac{\mathrm{RMR}-100}{18.75}}$ \\
\hline 3 & {$[27-28]$} & $\sigma_{\mathrm{cm}}=0.5 \mathrm{e}^{0.06 \mathrm{RMR}} \mathrm{MPa}$ \\
\hline 4 & [29] & $\frac{\sigma_{c m}}{\sigma_{c i}}=e^{\frac{R M R-100}{24}}$ \\
\hline 5 & [30] & $\frac{\sigma_{\mathrm{cm}}}{\sigma_{\mathrm{ci}}}=\mathrm{e}^{\frac{\mathrm{RMR}-100}{20}}$ \\
\hline 6 & [31] & $\frac{\sigma_{\mathrm{cm}}}{\sigma_{\mathrm{ci}}}=\frac{\mathrm{RMR}}{\mathrm{RMR}+6(100-\mathrm{RMR})}$ \\
\hline \multicolumn{3}{|r|}{ Based on RQD Classification } \\
\hline 7 & [32] & $\frac{\sigma_{\mathrm{cm}}}{\sigma_{\mathrm{ci}}}=10^{0.013 \mathrm{RQD}-1.34}$ \\
\hline \multicolumn{3}{|r|}{ Based on $Q$ value classification } \\
\hline 8 & [33] & $\sigma_{\mathrm{cm}}=7 \mathrm{Yf}_{\mathrm{c}} \mathrm{Q}^{1 / 3}(\mathrm{MPa})$ \\
\hline 9 & [34] & $\sigma_{\mathrm{cm}}=7 \mathrm{YQ}^{1 / 3}(\mathrm{MPa})$ \\
\hline 10 & [35] & $\sigma_{\mathrm{cm}}=5 \gamma\left(\frac{\mathrm{Q} \sigma_{\mathrm{c}}}{100}\right)^{\frac{1}{3}}(\mathrm{MPa})$ \\
\hline \multicolumn{3}{|r|}{ Based on GSI } \\
\hline 11 & {$[6]$} & $\begin{array}{l}\frac{\sigma_{c m}}{\sigma_{c i}} \\
=e^{\frac{G S I-100}{9-3 D}\left[\frac{1}{2}+\frac{1}{6}\left(e^{-\frac{G S I}{15}}-e^{-\frac{20}{3}}\right)\right]}\end{array}$ \\
\hline 12 & [32] & $\frac{\sigma_{c m}}{\sigma_{c i}}=0.036 e^{\frac{G S I}{30}}$ \\
\hline
\end{tabular}

Similar to the uniaxial compressive strength of rockmass, the elastic modulus (Emass) of the rock mass is also calculated using fourteen equations presented in Table IV. For some rockmass data elastic modulus of intact rock (Ei) is not provided. So only those equations which can predict the elastic modulus of rockmass without considering Ei have

TABLE IV VARIOUS ROCK MASS MODULUS CRITERION CONSIDERED FOR PRESENT STUDY

\begin{tabular}{|c|c|c|}
\hline $\begin{array}{l}\text { Sl. } \\
\text { No. }\end{array}$ & Reference & Criteria \\
\hline \multicolumn{3}{|r|}{ Based on RMR classification } \\
\hline 1 & {$[36]$} & $\begin{array}{l}E_{\text {mass }}=2 R M R-100(\mathrm{GPa}) \\
\text { For RMR }>50\end{array}$ \\
\hline 2 & {$[37]$} & $\begin{array}{l}E_{\text {mass }}=10^{\frac{(R M R-10)}{40}} \\
\text { For RMR }<50\end{array}$ \\
\hline 3 & {$[38]$} & $\begin{array}{l}E_{\text {mass }}=E_{i} * R F(\%) \\
\text { Where, } \\
R F(\%)=0.0028(R M R)^{2}+0.9 \mathrm{e}^{\frac{R M R}{22.82}}\end{array}$ \\
\hline 4 & [39] & $E_{\text {mass }}=10^{\frac{R M R-25}{40}}(\mathrm{GPa})$ \\
\hline 5 & {$[40]$} & $E_{\text {mass }}=E_{i}\left[0.5\left(1-\left\{\cos \pi \frac{R M R}{100}\right\}\right)\right]_{\mathrm{GPa}}$ \\
\hline 6 & [41] & $E_{\text {mass }}=0.1\left(\frac{R M R}{10}\right)_{\mathrm{GPa}}^{3}$ \\
\hline 7 & {$[42]$} & $E_{\text {mass }}=E_{i} \llbracket e^{\frac{R M R-100}{17.40}}$ \\
\hline \multicolumn{3}{|r|}{ Based on RQD Classification } \\
\hline 8 & {$[43]$} & $E_{\text {mass }}=E_{i} \square 0^{0.0186 R Q D-1.91}$ \\
\hline \multicolumn{3}{|r|}{ Based on $Q$ value classification } \\
\hline 9 & [44] & $\begin{array}{l}25 \log Q \\
\text { For } Q>1\end{array}$ \\
\hline 10 & {$[35]$} & $E_{\text {mass }}=10\left(\frac{Q \square \sigma_{c i}}{100}\right)^{1 / 3}$ \\
\hline 11 & {$[42]$} & $E_{\text {mass }}=E_{i} \llbracket e^{0.8625 Q-2.875}$ \\
\hline \multicolumn{3}{|r|}{ Based on GSI } \\
\hline 12 & [6] & $\begin{array}{l}E_{\text {mass }}=\sqrt{\frac{\sigma_{c i}}{100}} 10^{\frac{G S I-10}{40}} \\
\text { For } \sigma_{\mathrm{ci}}<100 \mathrm{MPa} \\
E_{\text {mass }}=10^{\frac{G S I-10}{40}} \\
\text { For } \sigma_{\mathrm{ci}}>100 \mathrm{MPa}\end{array}$ \\
\hline 13 & {$[45]$} & $E_{\text {mass }}=10^{2}\left(\frac{1-\frac{D}{2}}{1+\mathrm{e}^{\frac{75+25 D-G S I}{11}}}\right)_{\mathrm{GPa}}$ \\
\hline 14 & {$[45]$} & $E_{\text {mass }}=E_{i}\left(0.02+\frac{1-\frac{D}{2}}{1+\mathrm{e}^{\frac{60+15 D-G S I}{11}}}\right)_{\mathrm{GPa}}$ \\
\hline
\end{tabular}

been used. Fig.2 shows the typical Weibull's distributions fitted for calculation of elastic modulus of rockmass. The value of Emass for the rockmass is presented in Table V. For the GHB criterion only GSI classification system is used. The rockmass strength ( $\sigma \mathrm{cmass})$ and elastic modulus of rockmass (Emass) were calculated using equations which consider the GSI classification only. 
Table V present the value of both $\sigma \mathrm{cmass}$ _HB and Emass_HB calculated considering only GSI classification system.

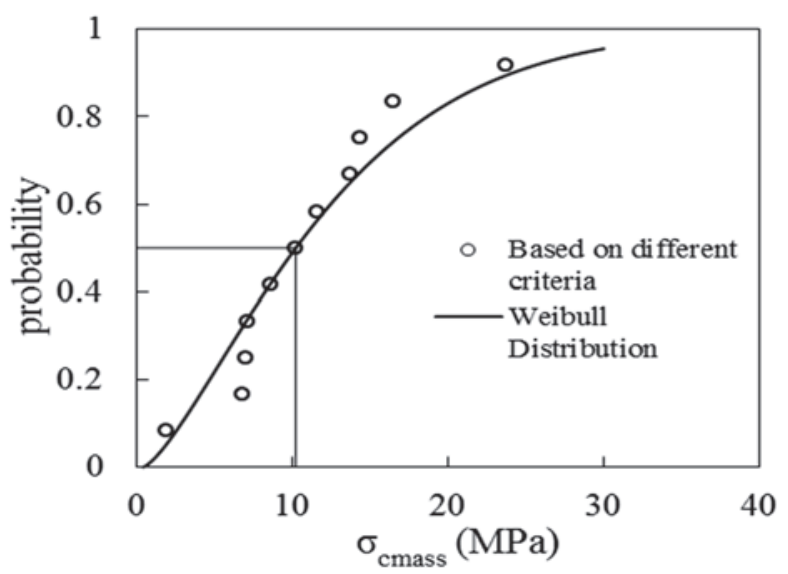

Fig.1. Typical Weibull's distribution curve for various rockmass strength value obtained from different criterion (for S1 No. 1)

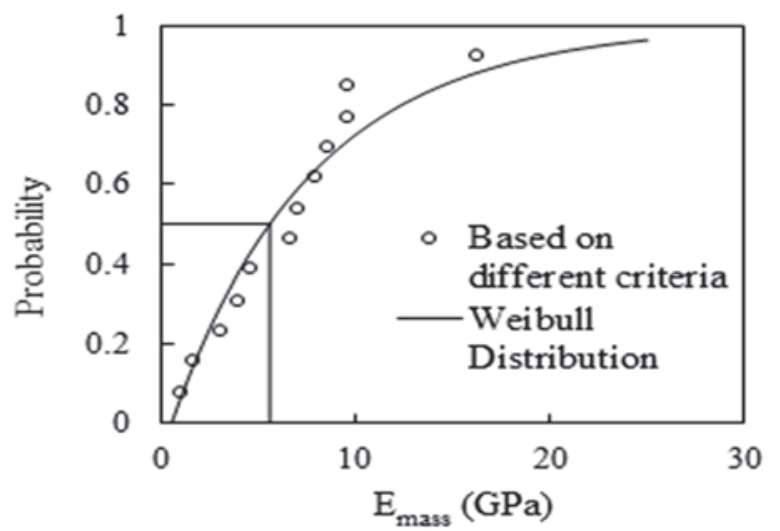

Fig.2. Typical Weibull's distribution curve for various rockmass modulus value obtained from different criterion (for S1 No. 1)

\section{B. Calculation of Modified Mohr-Coulomb Parameters}

The Sincio value as presented in Table $\mathrm{V}$ is used to calculate the value of Sin $\varphi$ jo using equation 2 . The SRF value is obtained using equation 3. Table $\mathrm{V}$ presents the parameters obtained for MMC criterion for all the rockmass.

\section{Using Generalised Hoek and Brown criterion}

The Generalised Hoek and Brown (GHB) criterion considers only GSI classification of the rockmass. The input parameters are GSI value for rockmass, mi and $\sigma \mathrm{c}$ value for the intact rock. The Roclab software is used to calculate the parameters of GHB criterion i.e. $\mathrm{mb}, \mathrm{S}$ and a value of the rockmass. The mi and $\sigma \mathrm{c}$ value as presented in Appendix-II and GSI value as presented in Table I are supplied to the software for calculating the parameters of GHB criterion for all the rockmass. Table VII present the parameters obtained for $\mathrm{GHB}$ criterion for all the rockmass.

\section{Poisson's ratio of Rockmass}

The Poisson's ratio for rockmass is considered as 1.2 times of poisons ratio of intact rock. The rockmass for which poisons ratio is not provided, a value of 0.25 is considered. Table VI and 7 also present the value of poisons ratio.

\section{ANALYSIS OF TUNNEL}

Carranza-Torres and Fairhurst [10] and Carranza-Torres [9] presented analytical solution for elasto-plastic analysis of circular tunnel subjected to uniform far-field stress. The strength criterion considered is Hoek-Brown criterion and Mohr Coulomb criterion. Three different analyses had been done in the present study. Firstly the GHB criterion had been applied directly using the analytical solution given CarranzaTorres and Fairhurst [10].

Secondly, the analysis is done considering the equivalent Mohr-Coulomb (EMC) parameters obtained by linearization of GHB criterion (EMC_GHB). Thirdly the analysis is done considering the EMC parameters obtained by linearization of MMC criterion (EMC MMC). For second and Third case, the analytical solution given by Carranza-Torres [9] has been used which consider Mohr-Coulomb Material.

TABLE V MMC AND GHB CRITERION PARAMETERS AND CORRESPONDING EMC PARAMETERS (FOR $0<\Sigma 3<10$ MPA)

\begin{tabular}{|c|c|c|c|c|c|c|c|c|c|c|}
\hline \multicolumn{11}{|c|}{ Modified Mohr Coulomb criterion } \\
\hline $\begin{array}{l}\text { DB } \\
\text { No. }\end{array}$ & $\sigma_{\mathrm{ci}}(\mathrm{MPa})$ & $\begin{array}{l}\sigma_{\text {cmass }}(\text { P50) } \\
\text { (MPa) }\end{array}$ & $\operatorname{Sin} \varphi_{\text {io }}$ & SRF & $\operatorname{Sin} \varphi_{\mathrm{jo}}$ & $\begin{array}{l}\mathbf{E}_{\text {mass }}(\mathbf{P 5 0}) \\
(\mathrm{GPa})\end{array}$ & $\begin{array}{l}\text { v } \\
\text { (Mass) }\end{array}$ & $\begin{array}{l}\mathbf{c}_{\mathrm{MMC}} \\
(\mathrm{MPa})\end{array}$ & $\begin{array}{l}\varphi_{\mathrm{MMC}} \\
\left({ }^{\circ}\right)\end{array}$ & $\begin{array}{l}\sigma_{c_{-} 1} \\
(\mathbf{M P a})\end{array}$ \\
\hline 1 & 93 & 6.825 & 0.7834 & 0.0734 & 0.8196 & 5.375 & 0.264 & 1.21 & 54.22 & 7.48 \\
\hline 2 & 142 & 10.216 & 0.8046 & 0.0719 & 0.8346 & 5.556 & 0.36 & 1.63 & 56.05 & 10.69 \\
\hline 3 & 62.3 & 6.163 & 0.7614 & 0.0989 & 0.8036 & 6.128 & 0.264 & 1.21 & 52.19 & 7.04 \\
\hline 4 & 64.7 & 4.792 & 0.7801 & 0.0741 & 0.8173 & 3.645 & 0.336 & 0.94 & 53.61 & 5.71 \\
\hline 5 & 43.85 & 3.935 & 0.7557 & 0.0897 & 0.8001 & 5.328 & 0.25 & 0.91 & 51.26 & 5.15 \\
\hline \multicolumn{11}{|c|}{ Generalised Hoek Brown Criterion } \\
\hline $\begin{array}{l}\text { DB } \\
\text { No. }\end{array}$ & $\begin{array}{l}\sigma_{\text {cmass_HB }} \\
(\mathrm{MPa})\end{array}$ & $\begin{array}{l}\mathbf{E}_{\text {mass_HB }} \\
\text { (GPa) }\end{array}$ & $\begin{array}{l}v \\
\text { (Mass) }\end{array}$ & $\begin{array}{l}\sigma_{\mathrm{c}} \\
(\mathrm{MPa})\end{array}$ & $\mathbf{m}_{\mathbf{b}}$ & $\mathbf{s}$ & $\mathbf{a}$ & $\begin{array}{l}\mathbf{c}_{\mathrm{HB}} \\
(\mathrm{MPa})\end{array}$ & $\begin{array}{l}\varphi_{\mathrm{HB}} \\
\left({ }^{\circ}\right)\end{array}$ & $\begin{array}{l}\sigma_{c_{-} 1} \\
(\mathbf{M P a})\end{array}$ \\
\hline 1 & 4.425 & 7.799 & 0.264 & 96.417 & 2.183 & 0.0025 & 0.508 & 2.23 & 41.31 & 9.85 \\
\hline 2 & 6.757 & 7.943 & 0.36 & 146.94 & 2.327 & 0.0025 & 0.508 & 2.74 & 45.10 & 13.28 \\
\hline 3 & 3.977 & 8.361 & 0.264 & 64.489 & 2.463 & 0.0043 & 0.505 & 2.08 & 38.97 & 8.72 \\
\hline 4 & 2.276 & 4.791 & 0.336 & 67.314 & 1.932 & 0.0014 & 0.511 & 1.67 & 37.65 & 6.90 \\
\hline 5 & 1.743 & 4.502 & 0.25 & 45.368 & 1.933 & 0.0018 & 0.509 & 1.49 & 34.42 & 5.66 \\
\hline
\end{tabular}




\section{A. Tunnel dimension and far field stress}

The tunnel considered for the present study is of radius (a) $5 \mathrm{~m}$ and subjected to far field stress $(\sigma 0)$ of $10 \mathrm{MPa}$. Fig. 3 shows the pictorial representation of problem considered.

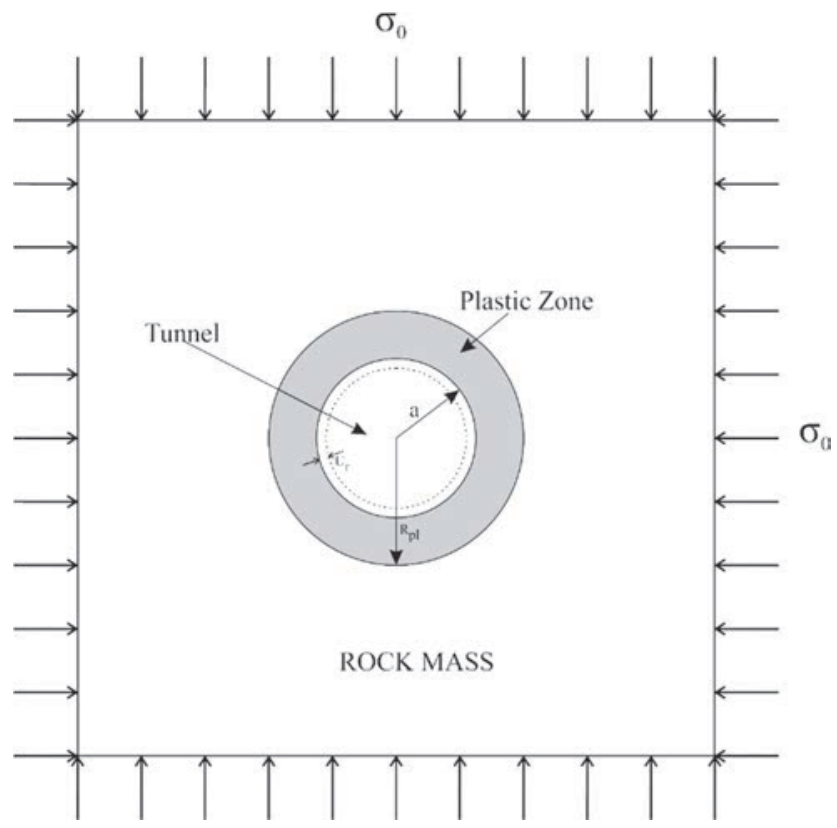

Fig.3. Hypothetical case of tunnel considered for the present study

\section{B. Analysis using GHB criterion directly}

The analysis of tunnel is done for non-associated case i.e. $\left(\psi=0^{\circ}\right)$ as well as for associated case $(\psi=\varphi)$ where $\psi$ is the dilatation angle. For the associated case the $\psi$ value is considered as angle of internal friction obtained from linearization of GHB criterion. The response of tunnel in terms of radius of plastic zone ( $\mathrm{Rpl})$, tunnel convergence (Ur) and tunnel convergence strain (Ur/a) for both non-associated and associated cases is presented in Table VI.

\section{Analysis using Linearization of GHB criterion}

Researchers worked on the GHB criterion for deducing the equivalent cohesion and angle of internal friction. Earlier Hoek et al. [5] stated that linearizing the eight triaxial data for minor principal stress in range of zero to $25 \%$ of UCS of intact rock can serve the purpose. However, the case is very different with tunnel as support pressure plays an important role in development of plastic zone around the opening. Artificial range of minor principal stress was defined by Hoek et al. [6] over which the linearization has to be done.

Sofianos and Halakatevakis [46] stated that in real field condition existing range of stresses has effect on equivalent Mohr-Coulomb criteria. Sofianos and Nomikos [47] compared various values of $\mathrm{c}$ and $\varphi$ calculated using linearization in existing range, artificial range of stresses and equating model response as stated by earlier researchers. Jimenez et al. [48] presented a technique for linearization of Hoek and Brown Criteria to calculate the equivalent cohesion and angle of internal friction by applying a best fit in lambe's p-q field.

The linearization of triaxial data of rockmass is done for the minor principal stress in range of Support pressure applied i.e. zero to Far field stress i.e. 10MPa. A best fit line equation is obtained using excel spreadsheet. The value of equivalent Mohr-Coulomb (EMC) parameters is calculated as:

$$
\begin{aligned}
& c=\frac{\sigma_{c_{-} 1}}{2 \sqrt{K}} \\
& \phi=\sin ^{-1}\left(\frac{K-1}{K+1}\right)
\end{aligned}
$$

where, equation of best fit line is presented as:

$$
\sigma_{1}=\mathrm{K} \sigma_{3}+\sigma_{\mathrm{c}_{-} 1}
$$

\begin{tabular}{|c|c|c|c|c|c|c|c|c|c|}
\hline $\begin{array}{l}\text { DB } \\
\text { No. }\end{array}$ & \multicolumn{3}{|c|}{$\begin{array}{l}\text { Generalized Hoek and Brown } \\
\text { (GHB) }\end{array}$} & \multicolumn{3}{|c|}{$\begin{array}{l}\text { Equivalent Mohr-Coulomb } \\
\text { Corresponding to Generalized } \\
\text { Hoek-Brown (GHB) Criterion } \\
\end{array}$} & \multicolumn{3}{|c|}{$\begin{array}{l}\text { Equivalent Mohr-Coulomb } \\
\text { Corresponding to Modified Mohr- } \\
\text { Coulomb (MMC) Criterion }\end{array}$} \\
\hline \multicolumn{10}{|c|}{ Non Associated Case } \\
\hline & $\mathrm{R}_{\mathrm{pl}}(\mathrm{m})$ & $\mathrm{U}_{\mathrm{r}}(\mathrm{mm})$ & $\mathrm{U}_{\mathrm{r}} / \mathrm{a}(\%)$ & $\mathrm{R}_{\mathrm{pl}}(\mathrm{m})$ & $\mathrm{U}_{\mathrm{r}}(\mathrm{mm})$ & $\mathrm{U}_{\mathrm{r}} / \mathrm{a}(\%)$ & $\mathrm{R}_{\mathrm{pl}}(\mathrm{m})$ & $\mathrm{U}_{\mathrm{r}}(\mathrm{mm})$ & $\mathrm{U}_{\mathrm{r}} / \mathrm{a}(\%)$ \\
\hline 1 & 5.63 & 9.32 & 0.186 & 5.71 & 9.07 & 0.181 & 5.52 & 13.08 & 0.262 \\
\hline 2 & 5.33 & 9.04 & 0.181 & 5.33 & 8.82 & 0.176 & 5.29 & 12.70 & 0.254 \\
\hline 3 & 5.85 & 9.00 & 0.180 & 5.96 & 8.78 & 0.176 & 5.63 & 11.78 & 0.235 \\
\hline 4 & 6.16 & 17.71 & 0.354 & 6.39 & 17.61 & 0.352 & 5.71 & 21.35 & 0.427 \\
\hline 5 & 6.73 & 21.34 & 0.427 & 7.04 & 21.45 & 0.429 & 5.91 & 14.66 & 0.301 \\
\hline \multicolumn{10}{|c|}{ Associated Case } \\
\hline 1 & 5.63 & 12.33 & 0.25 & 5.71 & 11.56 & 0.23 & 5.52 & 21.60 & 0.43 \\
\hline 2 & 5.33 & 10.38 & 0.21 & 5.33 & 9.54 & 0.19 & 5.28 & 15.55 & 0.31 \\
\hline 3 & 5.85 & 12.60 & 0.25 & 5.96 & 12.01 & 0.240 & 5.63 & 20.32 & 0.41 \\
\hline 4 & 6.16 & 27.04 & 0.54 & 6.39 & 27.51 & 0.55 & 5.71 & 42.79 & 0.85 \\
\hline 5 & 6.73 & 37.33 & 0.75 & 7.04 & 39.30 & 0.79 & 5.90 & 33.59 & 0.67 \\
\hline
\end{tabular}

TABLE VI RESPONSE OF TUNNEL CONSIDERING VARIOUS CONDITIONS OF STRENGTH CRITERION 
Table $\mathrm{V}$ present the EMC parameters obtained by linearization of GHB criterion in the range of 0 to $10 \mathrm{MPa}$. The EMC parameter is used to analyze the tunnel using analytical solution given by Carranza-Torres [9]. The response of tunnel in term of radius of plastic zone (Rpl), tunnel convergence (Ur) and tunnel convergence strain (Ur/a) for both non-associated and associated cases is presented in Table VI.

\section{Analysis using Linearization of MMC criterion}

Table $\mathrm{V}$ presents the equivalent $\mathrm{c}$ and $\varphi$ values obtained from linearization of triaxial data for the minor principal stress in the range of 0 to $10 \mathrm{MPa}$ for MMC criteria. The Analysis of the tunnel case has been done using the analytical solution given by Carranza-Torres [9] for Mohr-Coulomb material. The analysis is done using Excel spreadsheet. The analysis of tunnel is done for non-associated case i.e. $\left(\psi=0^{\circ}\right)$ as well as for associated case $(\psi=\varphi)$. The response of tunnel in term of radius of plastic zone (Rpl), tunnel convergence (Ur) and tunnel convergence strain (Ur/a) for both non-associated and associated cases is presented in Table VI.

\section{DISCUSSIONS}

\section{A. Ratio of equivalent cohesion and angle of internal friction}

Table VII present the ratio of equivalent cohesion and angle of internal friction obtain by linearization of GHB and MMC criterion for all the rockmass considered. The ratio of the equivalent cohesion of rockmass obtained by considering MMC criterion to that of cohesion obtained by considering GHB criterion is 0.57 . While the ratio of equivalent angle of internal friction is 1.36 .

TABLE VII RATIO OF EQUiVALENT MOHR-COULOMB PARAMETERS CONSIDERING MMC AND GHB CRITERION

\begin{tabular}{|l|l|l|}
\hline Sl No. & $\mathbf{C}_{\mathbf{M M C}} / \mathbf{C}_{\mathbf{H B}}$ & $\boldsymbol{\varphi}_{\mathrm{MMC}} / \boldsymbol{\varphi}_{\mathrm{HB}}$ \\
\hline 1 & 0.54 & 1.31 \\
\hline 2 & 0.59 & 1.24 \\
\hline 4 & 0.58 & 1.34 \\
\hline 5 & 0.56 & 1.42 \\
\hline 11 & 0.61 & 1.49 \\
\hline Average & 0.57 & 1.36 \\
\hline
\end{tabular}

\section{B. Radius of Plastic zone}

Fig.4 shows the radius of plastic zone for various rockmass cases. It can be clearly interpreted that the MMC criterion underestimates the radius of plastic zone as compared with that of GHB criterion. The radius of plastic zone predicted by $\mathrm{MMC}$ criterion is lower but close to that predicted by GHB criterion.

\section{Tunnel convergence Strain}

Fig.5 and Fig.6 shows the tunnel convergence strain calculate for various rockmass cases for associated and nonassociated case. The tunnel convergence strain predicted by MMC criterion is significantly overestimated as compared to that predicted by GHB criterion for both non associated and

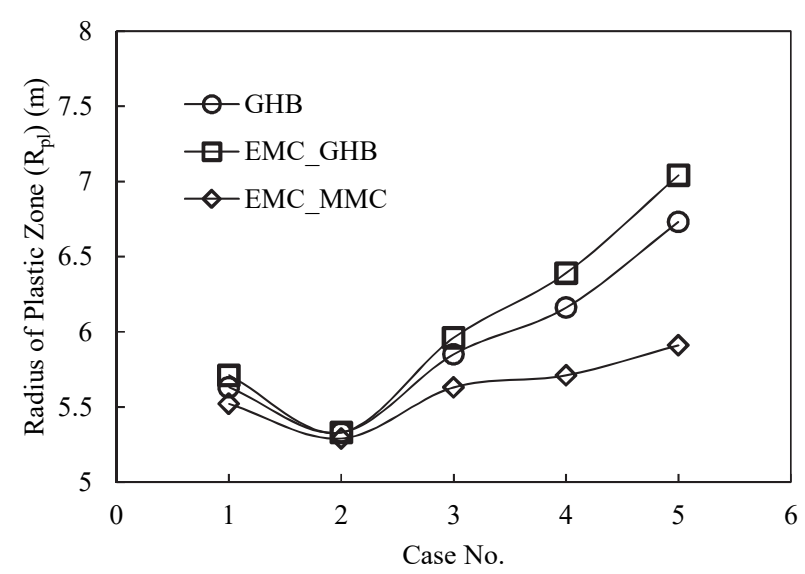

Fig.4. Radius of plastic Zone for various case

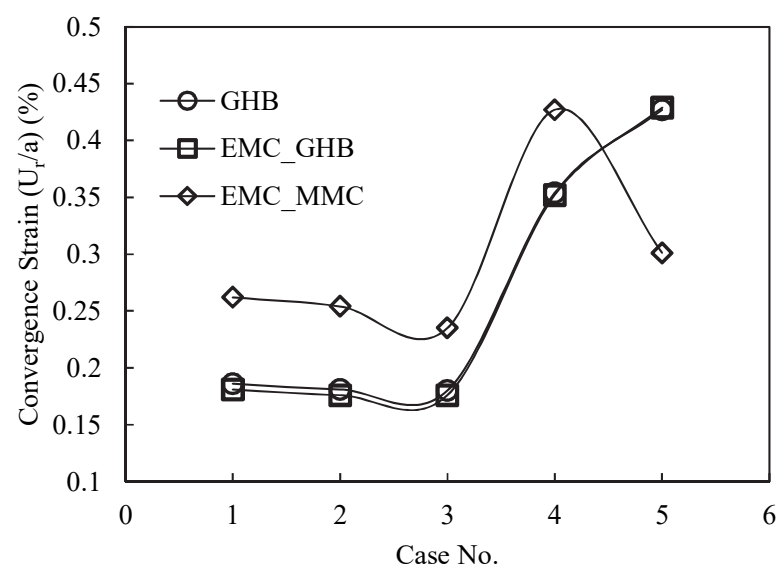

Fig.5. Tunnel convergence strain for various case (Non Associated case)

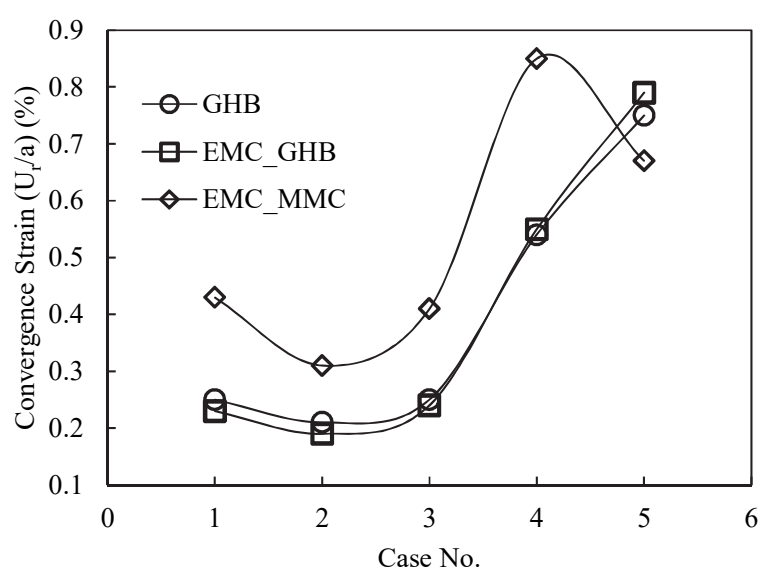

Fig.6. Tunnel convergence strain for various case (Associated case) associated case except for one case. However, the strain calculated from all the analyses is close.

\section{CONCLUDING REMARKS}

The present paper attempts to predict the value of triaxial strength of rockmass as well as an analysis of hypothetical tunnel case using Modified Mohr-Coulomb criterion. The 
rockmass data from twenty different sites were collected from literature. Weibull's probability distribution is used for determining a unique representative value of rockmass uniaxial strength and its elastic modulus. The triaxial strength of rockmass predicted by both GHB and MMC are compared based on equivalent Mohr-Coulomb (EMC) parameters. The MMC criterion predicts lower value of cohesion and higher value of angle of internal friction as compared to GHB criterion. The analysis of an unsupported case of tunnel has been carried out using the three different approaches. The analysis showed that for MMC criterion predict lower radius of plastic zone compared to GHB criterion. The tunnel convergence strains predicted for both non associated and associated case, the MMC criterion predict higher value as compared to GHB except for one case. The tunnel convergence strain is quite close to each other.

A quantitative comparison of Modified Mohr-Coulomb criterion with generalized Hoek-Brown criterion is presented in the present article. In the absence of actual data of tunnel convergence, it is very difficult to qualitatively compare the accuracy of both criterions.

The analysis of tunnel presented here above using MMC criterion consider a number of equation presented for estimation of strength and elastic modulus of rockmass. These equations were presented by a number of authors with their vast experience in field. The analysis also takes into account of various rock classification systems. The incorporation of probabilistic approach gives a much higher sense of confidence.

\section{ACKNOWLEDGEMENT}

The authors are grateful to Prof. Mahendra Singh, Department of Civil Engineering, IIT Roorkee for explaining Modified Mohr Coulomb Criterion in detail and suggestions regarding it.

\section{REFERENCES}

[1] D. Hobbs, 1966. "A study of the behaviour of broken rock under triaxial compression and its application to mine roadways", International Journal of Rock Mechanics and Mining Sciences, 3, pp. 11- 43.

[2] N. Barton, 1976, September. "The shear strength of rock and rock joints". International Journal of rock mechanics and mining sciences \& Geomechanics abstracts (Vol. 13, No. 9, pp. 255-279). Pergamon.

[3] E. Hoek. and E. T. Brown, 1980. "Empirical strength criterion for rock masses". Journal of Geotechnical and Geoenvironmental Engineering, 106 (ASCE 15715).

[4] P. R. Sheorey, A. K. Biswas, and V.D. Choubey, 1989. "An empirical failure criterion for rocks and jointed rock masses". Engineering Geology, 26, pp. 141-159.

[5] E. Hoek and E. T. Brown, 1997. "Practical estimates of rock mass strength". International Journal of Rock Mechanics and Mining Sciences, 34(8), pp.1165-1186.

[6] E. Hoek, C. Carranza-Torres, and B. Corkum, 2002. "Hoek-Brown failure criterion-2002 edition". Proceedings of NARMS-Tac, 1, pp.267-273.

[7] H. Rafiai, 2011." New Empirical polyaxial criterion for rock strength". International Journal of Rock Mechanics and Mining Sciences, 48(6), pp.922-931.

[8] M. Singh and B. Singh, 2012. "Modified Mohr-Coulomb criterion for non-linear triaxial and polyaxial strength of jointed rocks".
International Journal of Rock Mechanics and Mining Sciences, 51, pp.43-52.

[9] C. Carranza-Torres, 2003. "Dimensionless graphical representation of the exact elasto-plastic solution of a circular tunnel in a Mohr-Coulomb material subject to uniform far-field stresses". Rock Mechanics and Rock Engineering, 36 (3), pp. 237-253.

[10] C. Carranza-Torres, and C. Fairhurst, 1999. "The elasto-plastic response of underground excavations in rock masses that satisfy the Hoek-Brown failure criterion". International Journal of Rock Mechanics and Mining Sciences 36 (6), pp. 777-809.

[11] M. Singh, A. Raj, and B. Singh, 2011. "Modified Mohr-Coulomb criterion for non-linear triaxial and polyaxial strength of intact rocks". International Journal of Rock Mechanics and Mining Sciences, 48(4), pp.546-555.

[12] H. Sonmez and R. Ulusay, 1999. "Modifications to the geological strength index (GSI) and their applicability to stability of slopes". International Journal of Rock Mechanics and Mining Sciences, 36(6), pp.743-760.

[13] D. U. Deere, 1968. "Geological considerations. Rock Mechanics in Engineering Practice", eds. K.G.Stagg and O.C.Zienkiewicz. John Wiley \& Sons, London 1968, pp. 1-20

[14] Z. T. Bieniawski, 1976. "Rock mass classifications in rock engineering”. In: Z.T. Bieniawski (Editor), Symposium on Exploration for Rock Engineering. Balkema, Johannesburg, 1, pp. 97-106

[15] N. Barton, R. Lien, and J. Lunde, 1974. "Engineering classification of rock masses for the design of tunnel support”. Rock mechanics, 6(4), pp.189-236.

[16] E. Hoek, P. K. Kaiser and W. F. Bawden, 1995. "Support of underground excavations in hard rock". Rotterdam, Balkema, Brookfield, pp. 213

[17] A. Özsan and M. Akın, 2002. "Engineering geological assessment of the proposed Uruş dam, Turkey”. Engineering geology, 66(3), pp.271281.

[18] H. Basarir, A. Ozsan and M. Karakus, 2005. "Analysis of support requirements for a shallow diversion tunnel at Guledar dam site, Turkey". Engineering geology, 81(2), pp.131-145.

[19] F. I. Shalabi 2009, "Tunnel design based on empirical approaches: Raghadan Tunnel, Jordan". ITA sponsored Workshop "Underground structures in Hot Climate conditions" Riyadh, Saudi Arabia. 93-108

[20] F. I. Shalabi, H. A. Al-Qablan and O. H. Al-Hattamleh, 2009. "Elastoplastic behavior of Raghadan tunnel based on RMR and Hoek-Brown classifications". Geotechnical and Geological Engineering, 27(2), pp.237-248.

[21] J. Shen, R. Jimenez, M. Karakus, and C. Xu, 2014. "A simplified failure criterion for intact rocks based on rock type and uniaxial compressive strength". Rock mechanics and rock engineering, 47(2), pp.357-369.

[22] M. Singh and B. Singh, 2005. "A strength criterion based on critical state mechanics for intact rocks". Rock mechanics and rock engineering, 38(3), pp.243-248.

[23] P. Maheshwari, M. N. Viladkar and E. Venkatesham, 2009. "Modified Stanley's approach for statistical analysis of compression strength test data of rock specimens". International Journal of Rock Mechanics and Mining Sciences, 46(7), pp.1154-1161.

[24] M. Singh, V. Lakshmi, and L. P. Srivastava, 2015. "Effect of preloading with tensile stress on laboratory UCS of a synthetic rock". Rock Mechanica and Rock Engineering, 48 (1 ), pp 53-60.

[25] W. L. Yudhbir and F. Prinzl, 1983. "An empirical failure criterion for rock masses", Proc 5th International Congress on Rock Mechanics, 1, pp. B1-B8.

[26] T. Ramamurthy, G. V. Rao and K. S. Rao, (1985). "A strength criterion for rocks", Proc Indian Geotechnical Conference, 1, pp.59-64.

[27] M. R. Asef, D. J. Reddish and P. W. Lloyd, 2000. "Rock-support interaction analysis based on numerical modelling". Geotechnical and Geological Engineering, 18, pp.23-37.

[28] R. Trueman, 1988. "An evaluation of strata support techniques in dual life gate roads", Ph.D. thesis, University of Wales, Cardiff. 
[29] G. S. Kalamaras and Z. T. Bieniawski, 1995, January. "A rock mass strength concept for coal seams incorporating the effect of time". In 8th ISRM Congress. International Society for Rock Mechanics.

[30] P. R. Sheorey, 1997. "Empirical rock failure criteria", Balkema, Rotterdam.

[31] O. Aydan and S. Dalgic, 1998. "Prediction of deformation behavior of 3 lane Bolu tunnel through squeezing rock of north Anatolian fault zone (NAFZ)", Proc of Regional Symposium on Sedimentary Rock Engineering, pp. 228-233.

[32] L. Zhang, 2010. "Estimating the strength of jointed rock masses". Rock mechanics and rock engineering, 43(4), pp.391-402.

[33] B. Singh, and R. K. Goel, 1999. "Rock Mass Classifications - A Practical Approach in Civil Engineering", 1st edition, Elsevier Ltd, Amsterdam.

[34] B. Singh, M. N. Villadkar, N. K. Samadhiya. and V. K. Mehrotra, 1997. "Rock mass strength parameters mobilised in tunnels". Tunnelling and Underground Space Technology, 12(1), pp.47-54.

[35] N. Barton, 2002. "Some new Q-Value correlations to assist in site characteristics and tunnel design". International Journal of Rock Mechanics and Mining science, 39, pp. 185-216

[36] Z. T. Bieniawski, 1978. "Determining rock mass deformability experience from case histories". International Journal of Rock Mechanics and Mining science Geomechanics Abstract, 15.

[37] J. L. Serafim and J. P. Pereira, 1983, September. "Considerations of the geomechanics classification of Bieniawski". In Proceedings international symposium engineering geology and underground construction (Vol. 1, pp. 1133-1142).

[38] G. A. Nicholson and Z. T. Bieniawski, 1990. "A nonlinear deformation modulus based on rock mass classification". Internation Journal of Mining and Geological Engineering, 8, pp. 181-202.

[39] V. K. Mehrotra, 1992. "Estimation of Engineering Parameters of Rock Mass", Ph.D. thesis, University of Roorkee, Roorkee, India.

[40] H. S. Mitri, R. Edrissi, and J. Henning, 1994 "Finite element modeling of cable bolted slopes in hard rock ground mines". Presented at the SME annual meeting, New Mexico, Albuquerque. p. 94-116.

[41] S. A. L. Read, L. R. Richards, and N. D. Perrin, 1999. "Applicability of the Hoek-Brown failure criterion to New Zealand greywacke rocks". In Proceedings of the nineth international congress on rock mechanics, Paris, 2; pp. 655-60

[42] T. Ramamurthy, 2004. "A geo-engineering classification for rocks and rock masses". International Journal of Rock Mechanics and Mining Sciences, 41, pp 89-101.

[43] L. Zhang and H. H. Einstein, 2004. "Using RQD to estimate the deformation modulus of rock masses". International Journal of Rock Mechanics and Mining Sciences, 41(2), pp 337-341

[44] E. Grimstad and N. Barton, 1993. "Updating the Q system for NMT". In: Proceeding of international symposium on sprayed concrete, Fagernes, Norwgian Concrete Association, Norway, Oslo, PP. 20.

[45] E. Hoek and M. S. Diederichs, 2006. "Empirical estimation of rock mass modulus". International Journal of Rock Mechanics and Mining Science. 43, pp 203-215.

[46] A. L. Sofianos and N. Halakatevakis, 2002. "Equivalent tunnelling Mohr-Coulomb strength parameters for given Hoek-Brown ones". International Journal of Rock Mechanics and Mining Sciences, 39(1), pp.131-137.

[47] A. L. Sofianos and P. P. Nomikos, 2006. "Equivalent Mohr-Coulomb and generalized Hoek-Brown strength parameters for supported axisymmetric tunnels in plastic or brittle rock". International journal of rock mechanics and mining sciences, 43(5), pp.683-704.

[48] R. Jimenez, A. Serrano and C. Olalla, 2008. "Linearization of the Hoek and Brown rock failure criterion for tunnelling in elasto-plastic rock masses". International Journal of Rock Mechanics and Mining Sciences, 45(7), pp.1153-1163. 